\title{
A New Method to Measure Crack Extension in Nuclear Graphite Based on Digital Image Correlation
}

\author{
Shigang Lai, ${ }^{1}$ Li Shi, ${ }^{2}$ Alex Fok, ${ }^{3}$ Haiyan Li, ${ }^{3}$ Libin Sun, ${ }^{2}$ and Zhengming Zhang ${ }^{2}$ \\ ${ }^{1}$ Zhejiang Electric Power Design Institute Co., Ltd., China Energy Engineering Group, Zhejiang, China \\ ${ }^{2}$ Institute of Nuclear and New Energy Technology, Collaborative Innovation Center of Advanced Nuclear Energy Technology, \\ Tsinghua University, Beijing, China \\ ${ }^{3}$ Minnesota Dental Research Center for Biomaterials and Biomechanics, University of Minnesota, Minneapolis, MN, USA \\ Correspondence should be addressed to Li Shi; shili@mail.tsinghua.edu.cn
}

Received 30 December 2016; Revised 21 March 2017; Accepted 30 March 2017; Published 26 April 2017

Academic Editor: Leon Cizelj

Copyright (C) 2017 Shigang Lai et al. This is an open access article distributed under the Creative Commons Attribution License, which permits unrestricted use, distribution, and reproduction in any medium, provided the original work is properly cited.

Graphite components, used as moderators, reflectors, and core-support structures in a High-Temperature Gas-Cooled Reactor, play an important role in the safety of the reactor. Specifically, they provide channels for the fuel elements, control rods, and coolant flow. Fracture is the main failure mode for graphite, and breaching of the above channels by crack extension will seriously threaten the safety of a reactor. In this paper, a new method based on digital image correlation (DIC) is introduced for measuring crack extension in brittle materials. Cross-correlation of the displacements measured by DIC with a step function was employed to identify the advancing crack tip in a graphite beam specimen under three-point bending. The load-crack extension curve, which is required for analyzing the R-curve and tension softening behaviors, was obtained for this material. Furthermore, a sensitivity analysis of the threshold value employed for the cross-correlation parameter in the crack identification process was conducted. Finally, the results were verified using the finite element method.

\section{Introduction}

In the High-Temperature Gas-Cooled Reactor (HTGR) design, the fuel and control rods are contained and supported by graphite moderator bricks. Graphite is normally described as a brittle or quasi-brittle material with low fracture toughness [1]. Under irradiation, the material properties and dimensions of graphite change dramatically with the increase of dose $[2,3]$, which will create stresses high enough to cause brittle failure of the graphite components. As a result, the fuel and control rod channels may be breached, jeopardizing the operation and safety of HTGR. Therefore, it is important to consider the fracture behaviors of nuclear graphite at both the design and operation stages.

The fracture behaviors of brittle materials, including ceramic, concrete, rocks, and graphite, have been widely investigated [4-8]. Various failure criteria for nuclear graphite have been proposed and verified by experiments [911]. As the nonlinear fracture behavior of nuclear graphite is closely related to its grain size $[1,8]$, many researchers have focused on the studies of crack initiation, propagation, and failure of graphite materials with different grain sizes. $\mathrm{Su}$ et al. [12] carried out three-point bend tests with singleedge-notched beams (SENB) to measure the tension softening curves and Fracture Process Zone (FPZ) of a finegrain graphite. Similar tests were adopted for a coarsegrain graphite, NBG-18 [13]. Important fracture parameters, including the fracture toughness, FPZ, size effect, and Rcurve, which can be used for evaluating crack resistance in quasi-brittle materials were obtained. The compact tension [14] and double torsion tests [15], which are able to produce relatively stable cracks, have also been used to investigate the crack extension of graphite. In such studies, one primary requirement was to detect and monitor crack initiation and propagation. However, the failure of graphite is usually associated with fast unstable crack initiation and propagation, making it difficult to capture the process [16]. To date, many techniques have been employed to identify the crack position and measure its extension in situ during loading. Although the load-displacement curve can be used 
to determine the crack extension using the compliance of the cracked specimen [13], the compliance of the equipment and deviation of the material from linear-elastic behavior could introduce errors to the measurement. Another method for detecting crack extension is to measure the change in electric resistance between two electrodes placed on the opposite sides of the anticipated crack path [17]. When the crack propagates, the resistivity of the material will change accordingly. However, the results are sensitive to the environment since the resistivity of the sample is also a function of temperature and strain.

Consequently, noncontact imaging techniques have been developed for crack measurement. For example, Electronic Speckle Pattern Interferometry (ESPI) and X-ray microcomputed tomography (micro-CT) have been used to monitor crack growth in nuclear graphite [12, 15, 18]. ESPI can detect very small deformations on an object's surface but the measurement is affected by external disturbances such as mechanical vibrations. With micro-CT, the internal microcracks developed around the main crack were observed and the actual shape of the crack front was clearly revealed [18]. However, this method needed specially designed test equipment that could be fitted into the X-ray machine, and the scanning after each crack increment took a considerable amount of time to perform.

Digital image correlation (DIC) is an optical method which can also be used to measure the deformation and strain on an object's surface [19]. By analyzing a series of images recorded through a charge-coupled device (CCD) camera the whole displacement and strain fields can be calculated, from which the cracks on the material's surface can be identified. Compared to other methods, DIC has many advantages. For example, it is easy to set up, its measurement is in situ, fullfield, and noncontacting, and it can be used to detect large deformation [20]. Moreover, it can be used for measurement at high temperatures, which is often required for studying nuclear graphite. Not surprisingly, DIC has been widely used as an alternative method to monitor in situ the crack growth within structural materials, including nuclear graphite and functionally graded materials [21-24].

Although DIC has been shown to be a powerful tool for measuring crack extension, the accuracy of its results is uncertain. In order to identify the crack tip, a commonly used method is to define a strain threshold, $\varepsilon_{\text {th }}$, and the areas with strains higher than $\varepsilon_{\text {th }}$ are considered to be part of the crack [13-15]. The opening strain, which is an artificial strain caused by the crack opening displacement, was employed by Mostafavi et al. to visualize the cracks of different types of graphite [14]. A strain threshold of $1 \%$ was applied to the map of the maximum principal strain in their study. However, the position of the crack tip thus determined is rather sensitive to the value chosen for $\varepsilon_{\text {th }}$ and is greatly dependent on the resolution of the DIC results [19]. Additionally, methods using strains are not capable of identifying cracks on small specimens. Therefore, it is necessary to develop a less sensitive method for DIC that can be used to accurately identify the crack tip. In this study, the cross-correlation [25] algorithm was employed for the first time to process the displacement fields obtained from
TABLE 1: Material properties of NBG-18 [24].

\begin{tabular}{lcc}
\hline Properties & Unit & Value \\
\hline Mass density & $\mathrm{kg} / \mathrm{m}^{3}$ & 1873.24 \\
Modulus of elasticity & $\mathrm{GPa}$ & 11.9 \\
Poisson's ratio & - & 0.21 \\
Shear modulus of elasticity & $\mathrm{GPA}$ & 4.92 \\
$\begin{array}{l}\text { Coefficient of thermal } \\
\text { expansion }\end{array}$ & $\mathrm{l} /{ }^{\circ} \mathrm{C}$ & $4.54 \times 10^{-6}$ \\
\hline
\end{tabular}

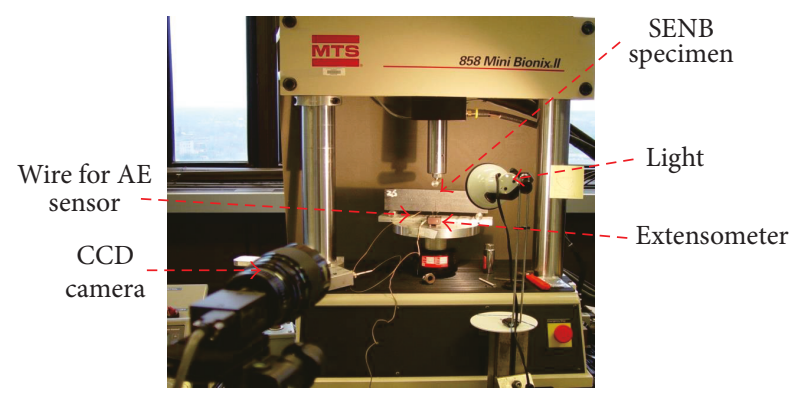

FIGURE 1: Setup of the three-point-bend test with a specimen in position.

DIC to identify the crack tip position in the specimens. A sensitivity analysis was conducted to test the convergence of this method. The results were verified through linear-elastic finite element (FE) simulations and good agreement between theory and experiment was achieved.

\section{Experiments}

Three-point-bend tests had previously been conducted using graphite single-edge-notched beams (SENB) and the fullfield distributions of displacement and strain were obtained through DIC [13]. The results for one group of these specimens were analyzed using the cross-correlation technique presented in this study.

2.1. Material and Specimens. The test material was a pitchcoke, vibrationally molded, near isotropic nuclear grade graphite NBG-18 (SGL Carbon Group, Germany). Its main material properties are listed in Table 1.

The dimensions of the SENB specimen analyzed in this study were $45 \mathrm{~mm}$ length, $10 \mathrm{~mm}$ width, and $5 \mathrm{~mm}$ thickness. A prenotch was cut into the specimen with a diamond blade (Buehler diamond wafering blade, $102 \mathrm{~mm} \times 0.3 \mathrm{~mm}$ ). The specimen had an initial crack length-to-width ratio of 0.4 , and the load span was $40 \mathrm{~mm}$.

2.2. Three-Point-Bend Test. The specimen was tested in threepoint bending using a universal MTS test machine (858 Mini Bionix II, MTS, US). The test setup is shown in Figure 1. A vertical displacement was applied to the specimen until it fractured completely. During loading, the notch mouth opening displacement was monitored continuously using an 


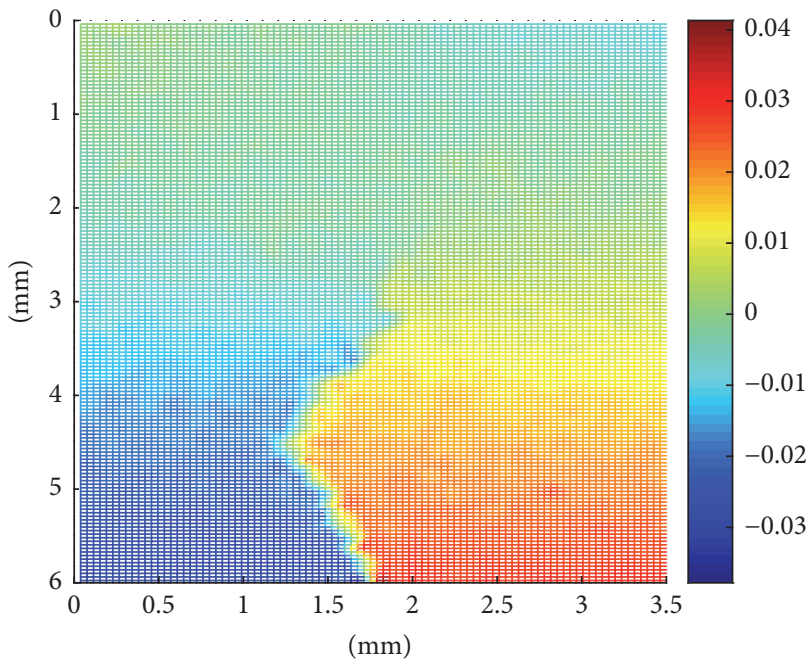

(a) Horizontal displacement $(\mathrm{mm})$, load $=18.128 \mathrm{~N}$

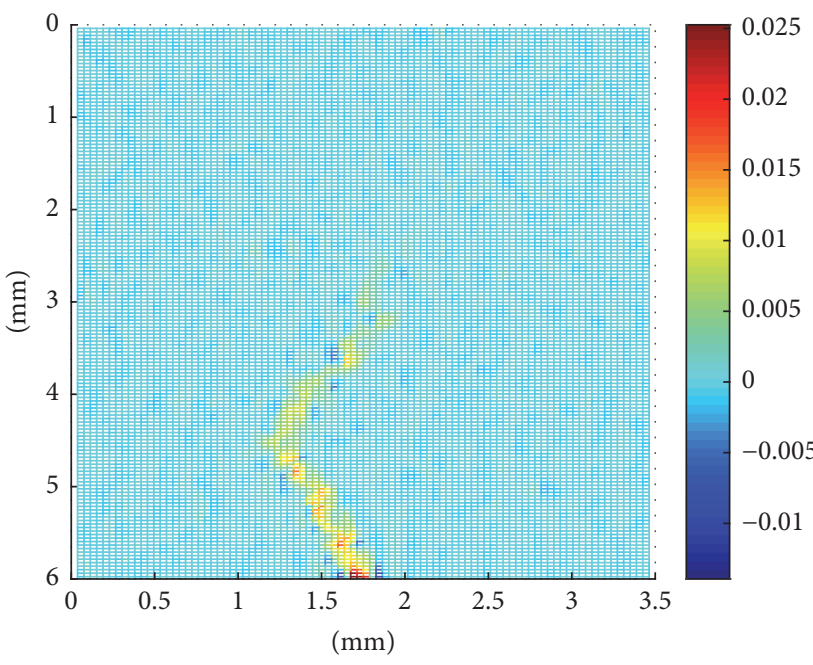

(c) Horizontal strain, load $=18.128 \mathrm{~N}$

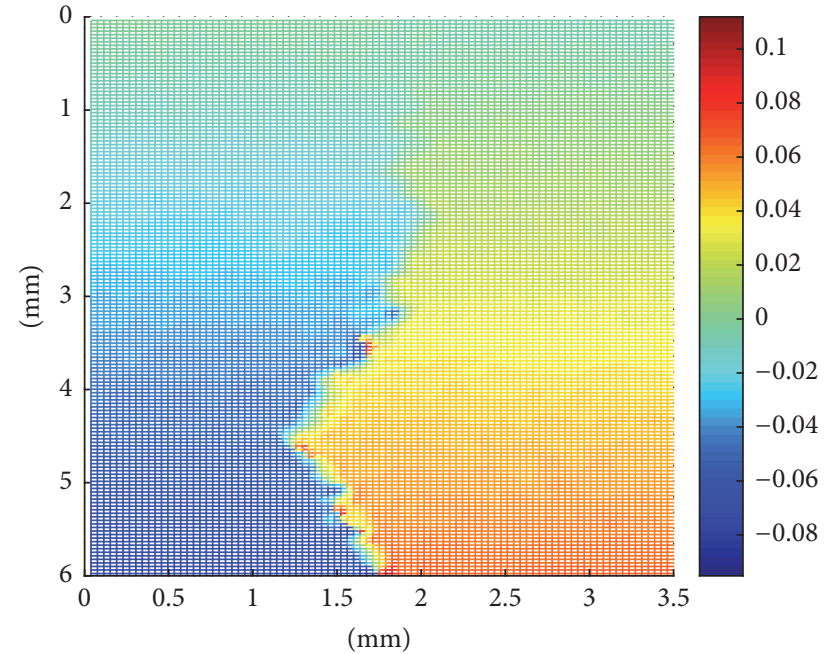

(b) Horizontal displacement $(\mathrm{mm}), \operatorname{load}=3.357 \mathrm{~N}$

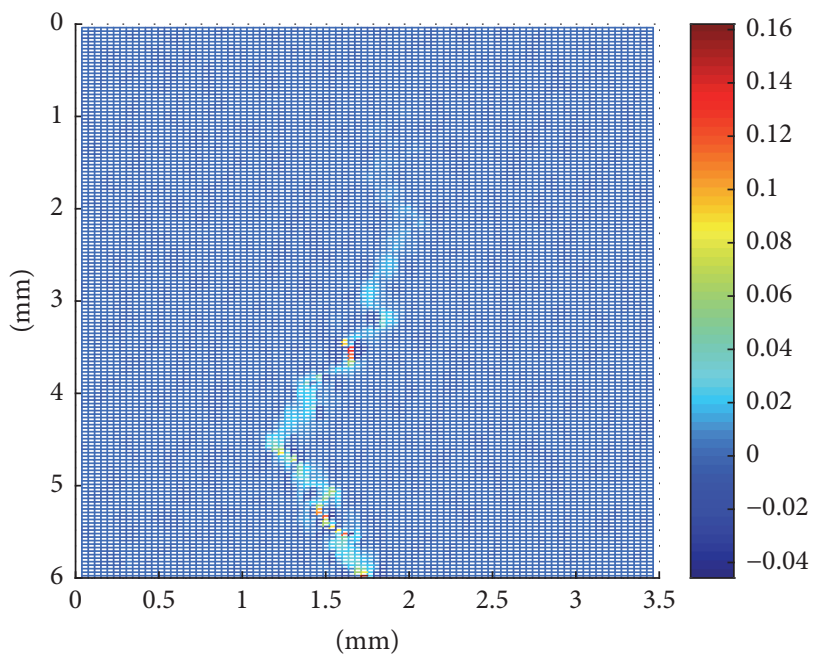

(d) Horizontal strain, load $=3.357 \mathrm{~N}$

FIGURE 2: Strain and displacement fields from DIC analysis under different postpeak loads.

extensometer for feedback control purposes so that stable postpeak load-displacement data were obtained.

During loading, a CCD camera (Point Grey Grasshopper GRAS-20S4C-C, Point Grey Research, Inc.) was used to take a series of pictures of the front surface of the specimen at a frequency of $7.5 \mathrm{~Hz}$ (Figure 1). To ensure accuracy of the DIC results, the surface of the specimen facing the camera was sprayed with a white paint to produce more irregularly shaped speckles, which facilitated the tracking of the surface displacements. The camera started to record at the same time as the loading process began.

2.3. Digital Image Correlation. The images recorded during the loading process were then analyzed by proprietary image correlation software (DAVIS, LaVision). Whole-field displacement and strain distributions of the front surface of the specimens were obtained. Multiple interrogations were used with a window size of $64 \times 64$ pixels at an overlap of $50 \%$ with two passes, followed by the use of $32 \times 32$-pixel windows at an overlap of $75 \%$ with two passes.

Figure 2 shows the distributions of the horizontal displacement and strain under two different loads from the DIC analysis. The images were taken at the postpeak stage when the crack was extending. Since the crack propagated mainly along the vertical direction, only the horizontal displacement and strain were used for crack identification.

Figure 3 shows the horizontal displacements along different horizontal paths. It can be seen that the displacements on the left side of the beam's centerline are negative, and those on the right side are positive. Within the upper uncracked area (Path $\mathrm{m} 3$ ), the horizontal displacement is close to zero, whereas within the lower cracked area (Paths $\mathrm{ml}$ and $\mathrm{m} 2$ ), there is a step change in the displacement curves at the position of the crack. 


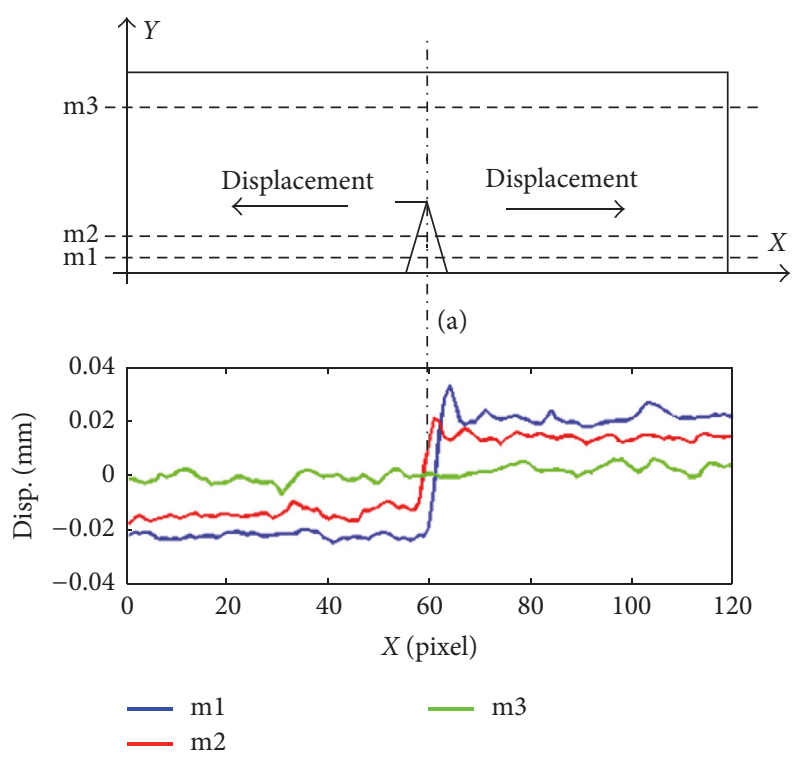

(b)

Figure 3: (a) Schematic diagram of SENB specimen under threepoint bending showing the positions of Paths $\mathrm{ml}, \mathrm{m} 2$, and $\mathrm{m} 3$; (b) horizontal displacement along Paths $\mathrm{m} 1, \mathrm{~m} 2$, and $\mathrm{m} 3$.

\section{Cross-Correlation Analysis}

In signal processing, cross-correlation is a measure of similarity between two waveforms as a function of a varying timelag applied to one of them. It is widely used to detect the time delay between two similar signals [25]. Cross-correlation is similar in nature to the convolution of two functions. As an example, consider two real valued functions $f$ and $g$ which are different only by an unknown shift along the $x$ axis. Cross-correlation can be used to find how much $g$ must be shifted along the $x$-axis to make it identical to $f$. The procedure essentially slides the $g$ function along the $x$-axis, calculating the summation of their product at each position. When the two functions match, the value of their crosscorrelation is maximized. This is because when the peaks and troughs are aligned, they both make a large positive contribution to the summation [22].

For discrete functions $f$ and $g$, the cross-correlation between them is defined as

$$
(f \circ g)[n] \stackrel{\text { def }}{=} \sum_{\tau=-\infty}^{\infty} f[\tau] g[n+\tau],
$$

where $\tau$ is the discrete time-lag and $f[n]$ and $g[m]$ are the $n$th element of function $f$ and the $m$ th element of function $g$, respectively.

The cross-correlation method was used here to trace the crack in the graphite specimen under three-point bending based on the displacement distributions from the DIC analysis. The scientific software Matlab [26] was used for programming the method.

3.1. Data Format. Each displacement field data obtained through DIC is stored as a two-dimension matrix, as shown

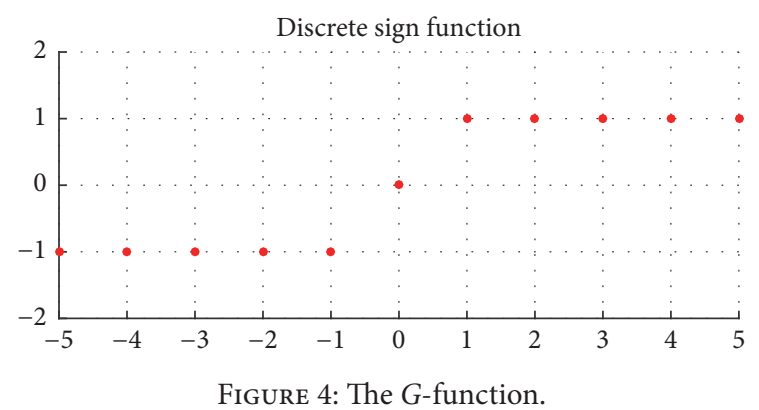

in Figures 2(a) and 2(b); the horizontal displacement at each sampling point was extracted and stored in the form of $M$ by- $N$ matrix:

$$
U: U(m, n) \quad m=1,2, \ldots, M ; n=1,2, \ldots, N
$$

or

$$
U=\left[\begin{array}{cccc}
u_{11} & u_{12} & \cdots & u_{1 N} \\
u_{21} & u_{22} & \cdots & u_{2 N} \\
\vdots & \vdots & u_{i j} & \vdots \\
u_{M 1} & u_{M 2} & \cdots & u_{M N}
\end{array}\right]
$$

where component $u_{i j}$ is the horizontal displacement in the $i$ th row and $j$ th column $M$ and $N$ are the total number of rows and columns, respectively, which are dependent on the resolution of the DIC analysis.

3.2. Cross-Correlation Process. Using each matrix $U$ extracted from the DIC results, a cross-correlation procedure was conducted to accurately map out the crack and to measure its extension. The process included two steps:

Step 1 (establishing the cross-correlation function $R$ and crack position array $P$ ). A discrete sign function $G$ is defined in (4). As shown in Figure 4, the shape of the $G$-function is similar to the distribution of horizontal displacement along a horizontal path crossed by the crack (Figure 3(b)).

$$
G(n)= \begin{cases}-1, & n \leq-1, \\ 0, & n=0 \\ 1, & n \geq 1\end{cases}
$$

For the $M$ rows of horizontal displacement, the crosscorrelation function between the $G$-function and the matrix $U$ was constructed as

$$
\begin{aligned}
R(m, \tau)=\sum_{\tau}^{N} U(m, n) G(n-\tau), & \\
& m=1,2, \ldots, M ; n=1,2, \ldots, N,
\end{aligned}
$$

where $R$ is the cross-correlation function, $m$ is the row number, $n$ is the column number, and $\tau$ is an integer variable 


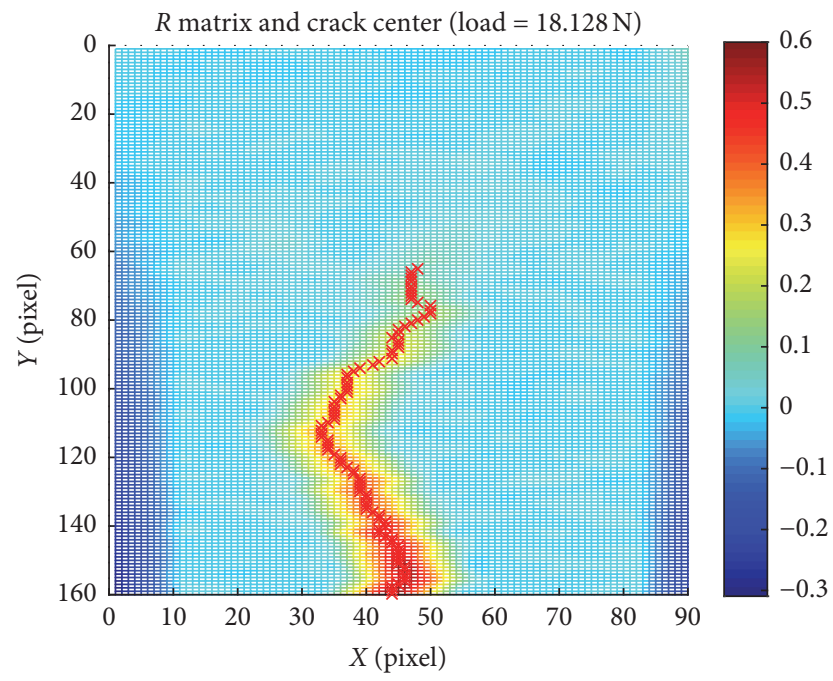

(a)

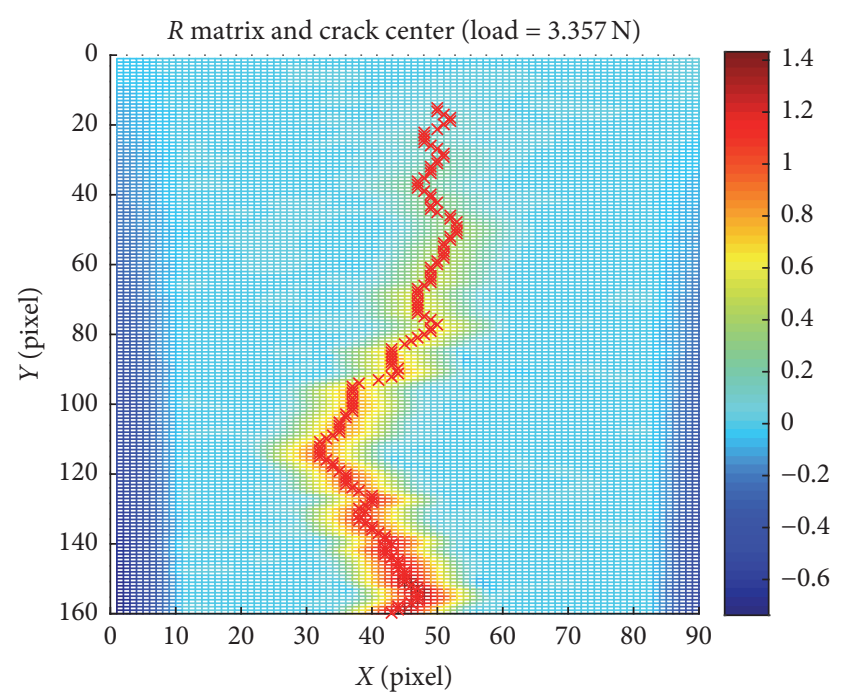

(b)

Figure 5: Maps of the cross-correlation function $R$ and crack position $P$ under (a) Load 1 (18.128 N) and (b) Load 2 (3.357 N).

representing the shift. Therefore, by shifting $G$, the closer it was in matching its step to that of a particular row of entries in $U$, the larger the corresponding value in the cross-correlation function $R$ is. In this way, the dissimilarity between the cracked and uncracked areas was actually enlarged with the cross-correlation analysis. Note that the cross-correlation function $R$ was also an $M$-by- $N$ matrix.

Along the $m$ th row, $R$ reached its maximum value where the shift in $G$ matched its step with that in the horizontal displacement curve best. This coincided with the crack position. So the crack position was identified by finding the maximum value of $R$ along each row. An array $P$ was thus constructed to store the crack position (column number) in each row:

$$
P(m)=n \_\max , \quad m=1,2, \ldots, M,
$$

where $n$ max is the column number with the maximum $R$ in the $m$ th row; that is, $R\left(m, n \_\max \right)=\max (R(m, n))$. Figure 5 shows the maps of the matrix $R$ and the array $P$ (marked by red crosses) under the same Load 1 and Load 2 as in Figure 2.

Step 2 (identification of the crack tip). After obtaining the crack position array $P$, the next task was to accurately identify the crack tip. To do so, an array $V$ was introduced to store the variance of the cross-correlation function $R$ on each row:

$$
V(m)=\operatorname{Var}(R(m, n)) .
$$

The variance function was defined by the following equation:

$$
\operatorname{Var}(X)=E\left[(X-\mu)^{2}\right]
$$

where $X=\left[x_{1}, x_{2}, \ldots, x_{n}\right]$ and $\mu$ is the mean value of $X$.

With the variance array $V$, the dissimilarity between the cracked and uncracked areas was further enlarged. The crack tip was then positioned by defining the cracked area as the area where $V \geq V_{\text {th }}, V_{\text {th }}$ being a threshold of $V$ (see later). And the complete crack was fully captured by combining the crack position array $P$ and the variance array $V$ that defined the crack tip.

Figures 6(a) and 6(c) show the distributions of $V$ along the vertical direction for images under Load $1(18.128 \mathrm{~N})$ and Load $2(3.357 \mathrm{~N})$, respectively. In Figure 6(a), the value of $V(m)$ tends towards $9 \times 10^{-4}$ as it enters the uncracked region. Figures 6(b) and 6(d) show the delineated cracks using a threshold for $V$ of $V_{\text {th }}=9 \times 10^{-4} \mathrm{~mm}^{2}$.

3.3. Crack Extension versus Load. The above analysis was repeated for all the images and the crack extensions under different load levels were obtained, as shown in Figure 7. Each point on the curve represents the results from one DIC image. The curve shows that crack propagation started just before the peak load and the crack propagated steadily thereafter with a decrease in load.

3.4. Sensitivity Analysis. In the crack identification process, a threshold, $V_{\text {th }}$, for the variance was required to locate the crack tip. In order to study how much the results were dependent on $V_{\text {th }}$, a sensitivity analysis was conducted by measuring the crack extension with different $V_{\text {th }}$, as shown in Figure 8(a). It can be seen that as $V_{\text {th }}$ decreased, the calculated crack length increased. But the results converged quickly, and when $V_{\text {th }}$ was smaller than $1.5 \times 10^{-3}$, the curves were almost the same.

For comparison, the crack extension was also calculated using two other methods that were based on (1) the displacement field $U$ without the cross-correlation analysis and (2) the strain fields. These two methods also required a threshold value for their respective parameters, displacement and strain, to identify the crack tip. The results are shown 


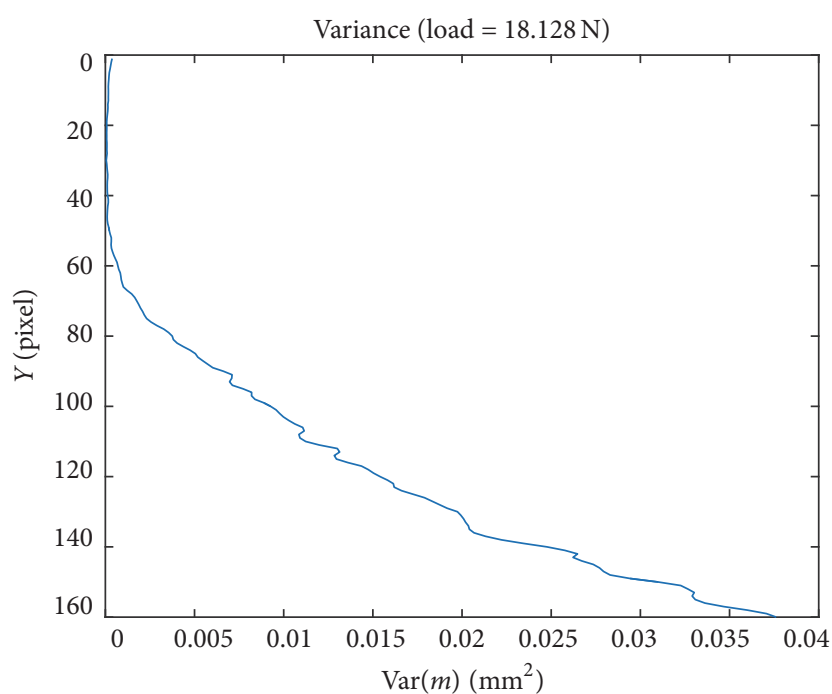

(a)

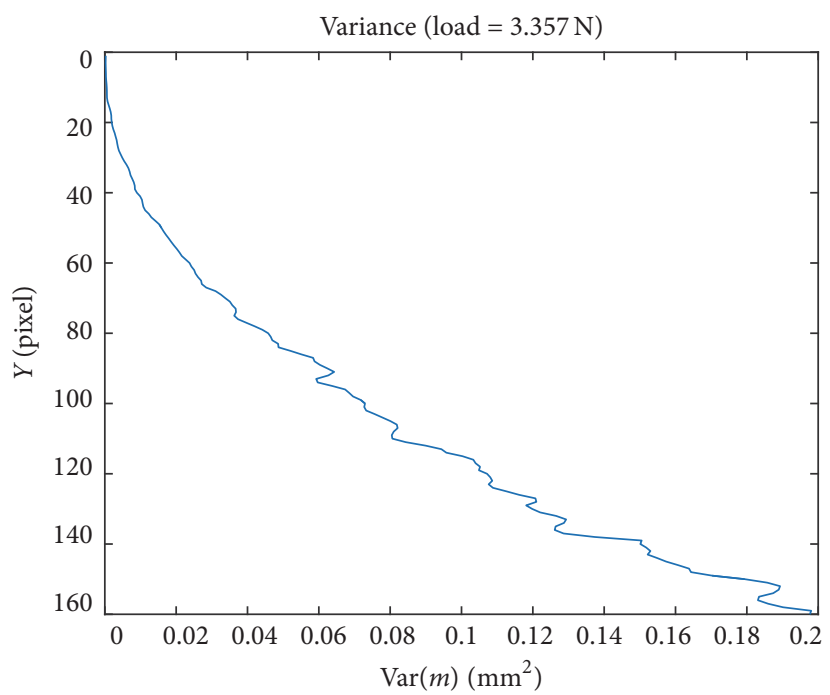

(c)

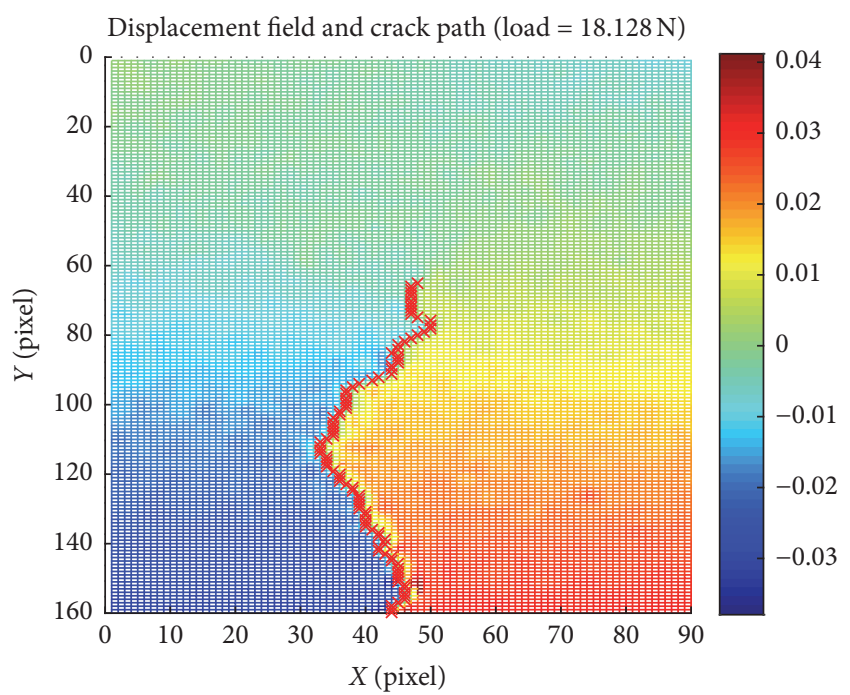

(b)

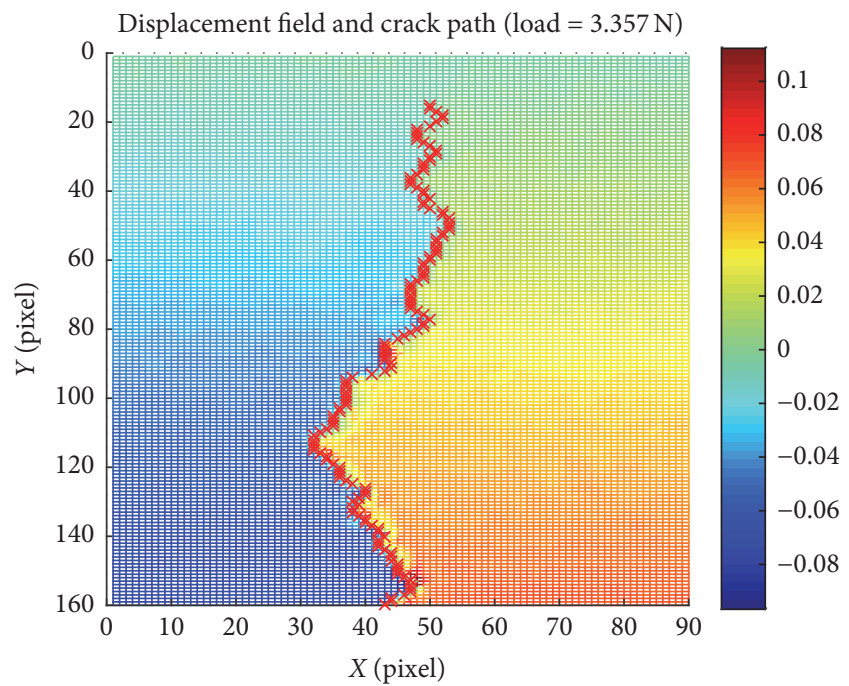

(d)

FIGURE 6: Distributions of $V$ and delineated cracks on the displacement maps under different loads.

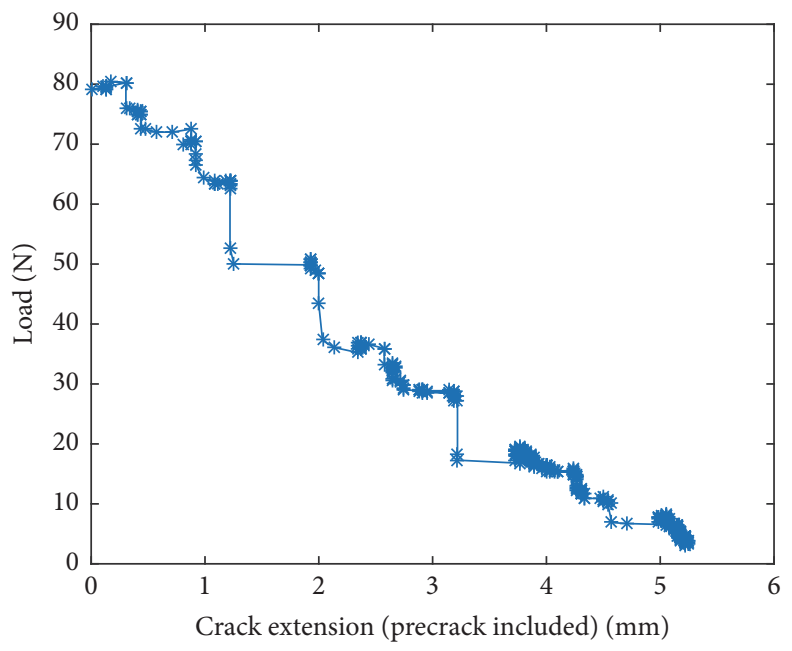

FIGURE 7: Load versus crack extension. 


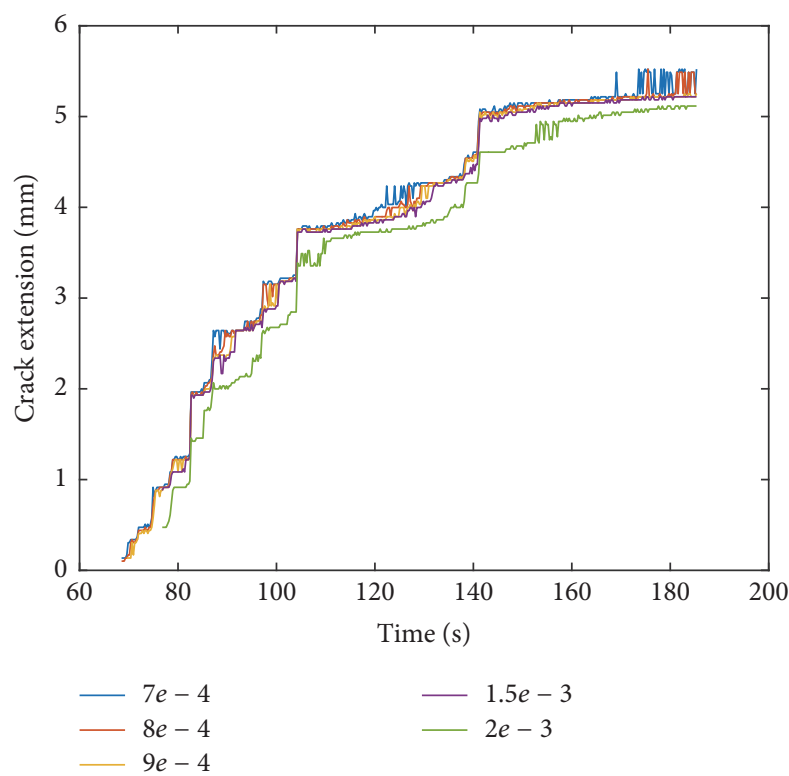

(a)

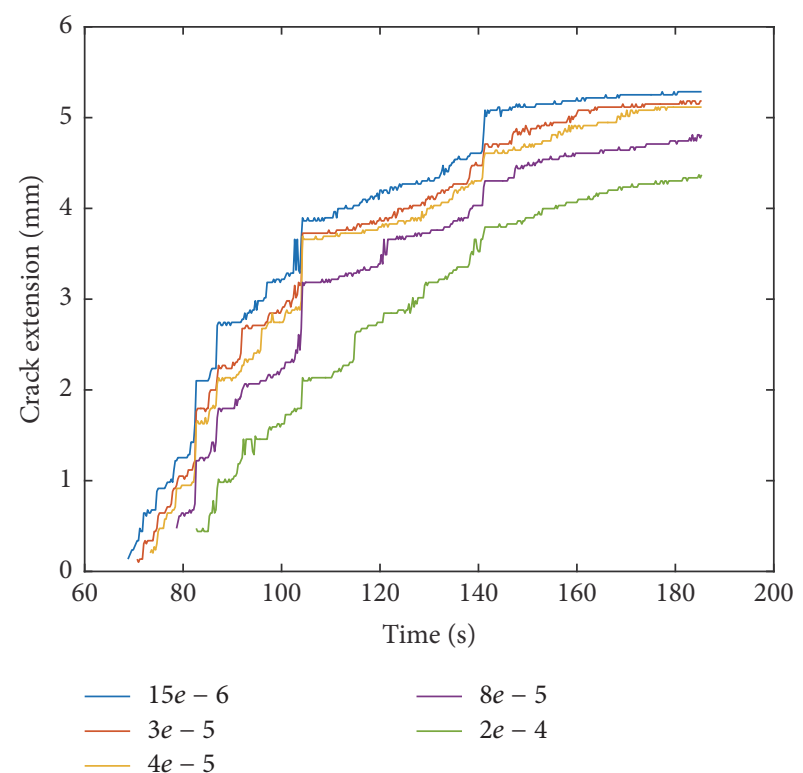

(b)

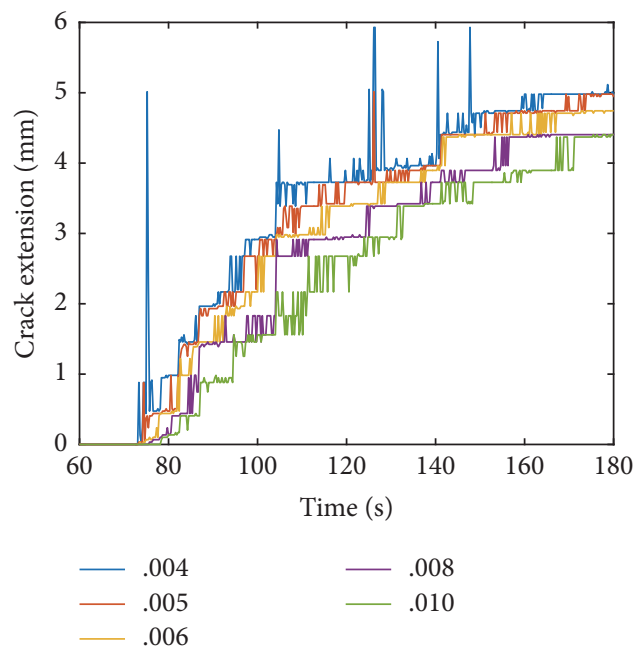

(c)

FiguRE 8: Crack extensions using different threshold parameters based on (a) displacement map with cross-correlation analysis, (b) displacement map without cross-correlation analysis, and (c) strain map without cross-correlation analysis.

in Figures 8(b) and 8(c). It can be seen that their speeds of convergence were much slower than that based on the cross-correlation of displacement functions, as shown in Figure 8(a), indicating that their results were more sensitive to the threshold.

\section{Verification with the Finite Element Method}

In order to verify the results obtained from the crosscorrelation process, the finite element (FE) method was used to predict the crack extension versus load for the same specimen. The dimensions of the specimen were given in Section 2.1.

Cracks with different lengths, from $0 \mathrm{~mm}$ to $5 \mathrm{~mm}$, were considered in the FE analysis using ABAQUS. Figure 9(a) shows one of the FE models with a crack of $1 \mathrm{~mm}$ long ahead the notch. The mesh around the crack tip was refined. Loading and supporting components were considered in the model and hard contacts were assumed between these components and the graphite specimens. The FE model contained 6904 8-node, plane-strain elements (CPE8) and 20939 nodes. The material was assumed to be linear-elastic, with the same parameters as those in Table 1.

The FE-predicted load-displacement curves (green) for different crack lengths were plotted together with one of the test results (blue) in Figure 9(b). It can be seen that with the increase of crack extension, the slopes of the green lines decreased, indicating a decrease in stiffness of the specimen. The loads corresponding to the different crack extensions were obtained from the intersection points between the 


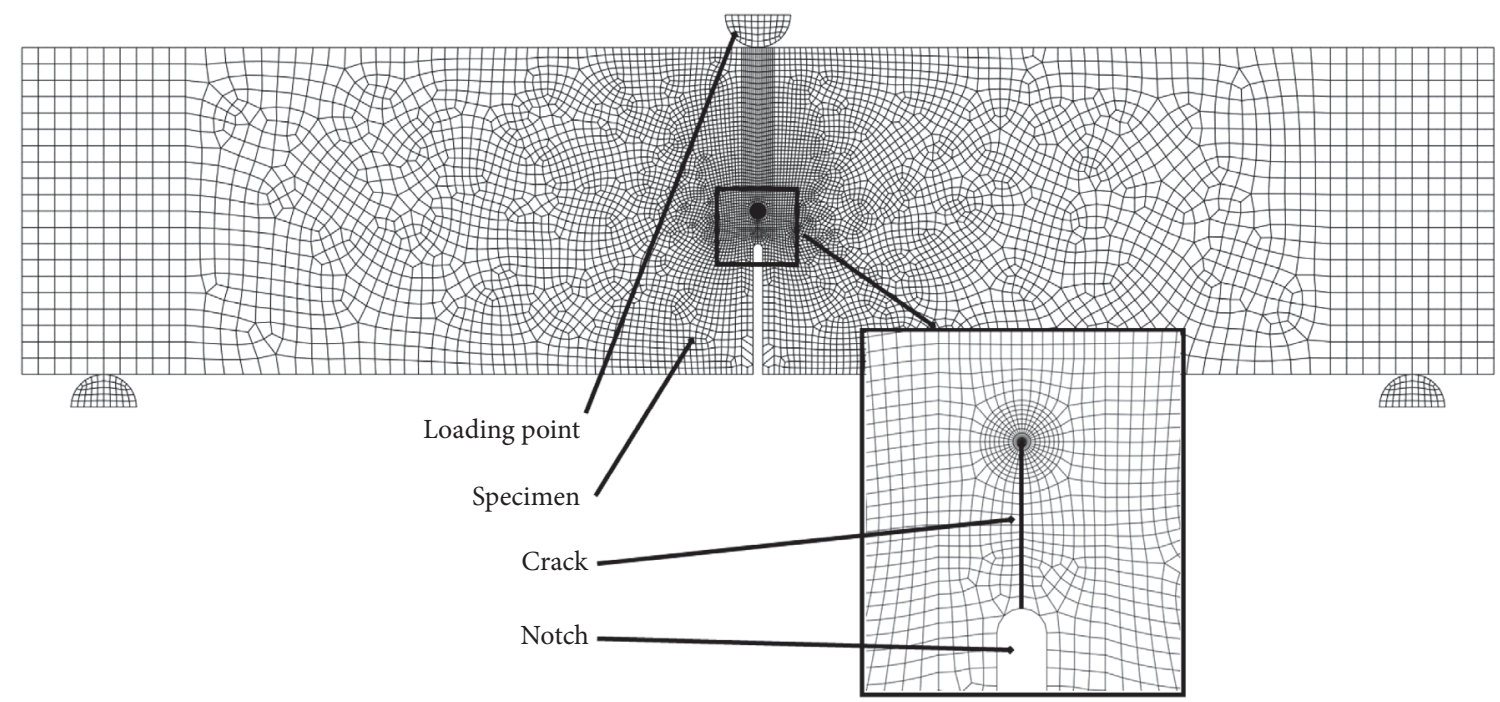

(a)

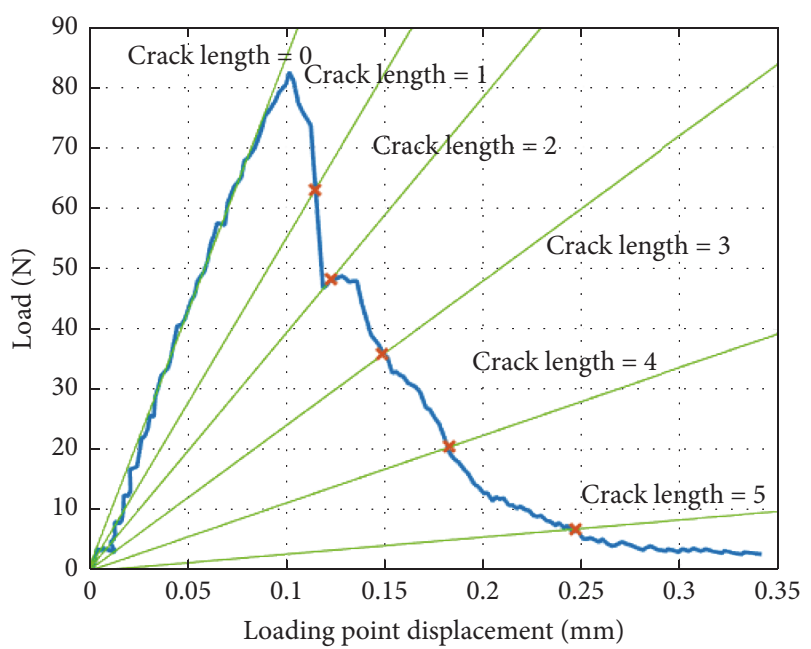

(b)

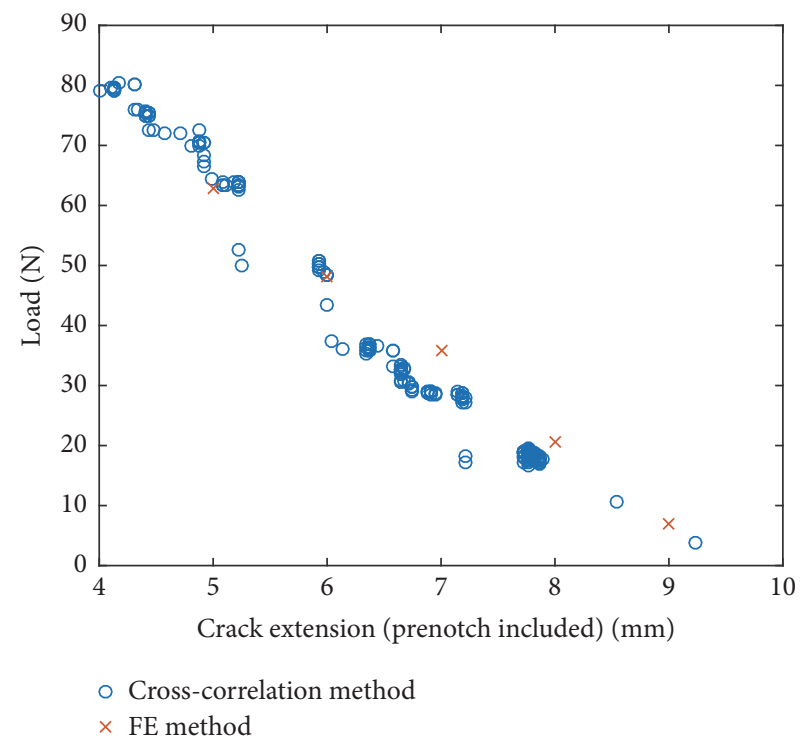

(c)

Figure 9: FE simulation: (a) FE model, (b) FE-predicted load-displacement curves (green) for models with different crack lengths intersecting with the experimental load-displacement curve (blue), and (c) FE and cross-correlation results for the load-crack extension curve.

experimental load-displacement curve and the FE-simulated load-displacement lines, as shown in Figure 9(b). The crack length as a function of load in the test can thus be estimated. The intersection points in the figure are listed in Table 2. The procedure is similar to that used by Hodgkins et al. to observe the microstructural damage and crack morphology in graphite [27]. In their study, the specimen was unloaded and reloaded during crack propagation and the crack length was calculated from the unloading compliance. In the present study, FE simulations were used instead to obtain the compliance of the cracked specimen.

Figure 9(c) shows the load versus crack extension behavior predicted by the FE analysis, together with those from the cross-correlation analysis. It can be seen that the two sets of results agreed well with each other. The results given by the cross-correlation method were slightly lower than those from the FE simulation.

\section{Discussion and Conclusion}

Digital image correlation (DIC) has been widely used to monitor the failure of engineering materials because of its capability to provide in situ, full-field, and noncontacting deformation measurement.

In a DIC analysis, the displacement field is the primary result obtained directly from the correlation analysis of the raw images, while the strain field is a secondary result which is obtained through the differentiation of the displacement 
TABLE 2: FE simulation results.

\begin{tabular}{lccc}
\hline Crack extension/mm & $\begin{array}{c}\text { Crack extension } \\
\text { including prenotch }\end{array}$ & Loading point Disp./mm & Load/N \\
\hline 1 & 5 & 0.115 & 62.89 \\
2 & 6 & 0.123 & 48.12 \\
3 & 7 & 0.149 & 35.71 \\
4 & 8 & 0.183 & 20.54 \\
5 & 9 & 0.246 & 6.975 \\
\hline
\end{tabular}

field. Therefore, the displacement field provides more detailed information on the crack profile than the strain field. However, unlike strain, the values of displacement could not be directly related to the crack. Therefore, a cross-correlation method was developed in this study to more accurately identify the tip of an advancing crack and measure its extension at different stages of loading from the displacement field.

The crack length identified is dependent on the threshold set for the parameter used in the identification, which may in turn depend on the material properties, specimen size, and loading conditions. This is reflected in the different strain thresholds, $\varepsilon_{\text {th }}$, employed in the literature. For the threepoint bend test [13], as fracture occurred rapidly, the detected crack length was found to be very sensitive to $\varepsilon_{\text {th }}$. To find the proper $\varepsilon_{\text {th }}$, crack extension curves for different threshold values were compared and the one which could describe the experimental results best was adopted. Strain thresholds of $0.4 \%$ and $0.7 \%$ were chosen for large- and small-size specimens, respectively. Compared to the SENB specimen, compact tension and double torsion specimens were able to produce more stable crack growth and the measured crack length based on the strain map was less sensitive to $\varepsilon_{\mathrm{th}}$. However, the selection of the threshold strain is still based on experience or trial and error, depending on the application. A threshold value of $1 \%$ was used to calculate crack length and $0.5 \%$ was chosen to identify microcracking in [14]. In a later study using the double torsion technique [15], the threshold strain for identifying microcracking was $0.35 \%$, which was about twice the maximum predicted strain of the material assuming linear elasticity.

Similar to methods that are based on strain maps, a threshold for the variance $V$ is also required in the crosscorrelation method in order to locate the crack tip. However, the sensitivity analysis showed that the results with the cross-correlation analysis were much less dependent on the threshold adopted. As shown in Figure 8, the results based on the cross-correlation method converged fastest. In addition, the crack profile could be more accurately defined with this method, as shown in Figure 5.

The crack extension-load curve obtained with the crosscorrelation method was verified through $\mathrm{FE}$ analysis. As shown in Figure 9(c), the crack extensions given by the FE simulations were slightly longer than those from the crosscorrelation method. This was reasonable because the linearelastic material behavior assumed in the FE model could result in a higher stiffness of the specimen, causing an overestimation of the load for a certain crack extension. In reality, the stress-strain curve of graphite is slightly nonlinear and there is a Fracture Process Zone ahead of the crack tip which leads to inelastic behavior.

Based on the characteristics of the displacement distribution across a crack, a $G$-function (see (1)) was defined to enlarge the difference between the cracked and uncracked areas through cross-correlation. It should be noted that the $G$-function in (1) is only suitable for mode I cracks, such as those produced under tensile, three-point, and four-point bending tests. For specimens with other fracture modes, the aforementioned $G$-function should be revised according to the characteristics of the displacement distribution.

Although the cross-correlation method presented in this paper was developed to trace the single crack, it can be extended to identify multiple cracks in specimens under complex loading. For example, cross-correlation analyses along the $x$ - and $y$-directions can be conducted jointly to map out crack trajectories in different directions.

In conclusion, the cross-correlation method developed in this study is a robust way to identify the path of an advancing crack based on DIC results. The main advantages of this method include the following: (1) the crack extension can be measured accurately; (2) the profile of the crack can be clearly identified; and (3) the results are less sensitive to the calculation parameters. The developed method will improve the current measurement of crack propagation of nuclear graphite and lead to a better understanding of its fracture behaviors, which is essential for the design and safe operation of HTGR.

\section{Nomenclature}

CCD: Charge-coupled device

DIC: Digital image correlation

ESPI: Electronic Speckle Pattern Interferometry

FE: $\quad$ Finite element

FPZ: $\quad$ Fracture Process Zone

HTGR: High-Temperature Gas-Cooled Reactor

SENB: Single-edge-notched beams

$U: \quad$ Displacement field

$V: \quad$ Variance array

$\varepsilon: \quad$ Strain

$\varepsilon_{\text {th }}$ : Strain threshold.

\section{Conflicts of Interest}

The authors declare that they have no conflicts of interest. 


\section{Acknowledgments}

This research was performed using funding received from the DOE Office of Nuclear Energy's Nuclear Energy University Programs. The authors would like to acknowledge Minnesota Dental Research Center for Biomaterials and Biomechanics (MDRCBB) for providing the testing devices and the Minnesota Supercomputing Institute (MSI) for providing the computing services.

\section{References}

[1] T. D. Burchell, Ed., Carbon Materials for Advanced Technologies, Elsevier, Amsterdam, Netherlands, 1999.

[2] H. Matsuo, T. Saito, and Y. Sasaki, "Effects of high temperature neutron irradiation on dimension and thermal expansion coefficient of nuclear grade graphites," Journal of Nuclear Science and Technology, vol. 18, no. 11, pp. 863-869, 1981.

[3] H. Matsuo and T. Saito, "Irradiation behaviors of nuclear grade graphite in commercial reactor, (I) dimensional change and thermal expansion," Journal of Nuclear Science and Technology, vol. 22, no. 2, pp. 139-146, 1985.

[4] S. P. Shah, S. E. Swartz, and C. Ouyang, Fracture Mechanics of Concrete: Applications of Fracture Mechanics to Concrete, Rock and Other Quasi-Brittle Materials, John Wiley \& Sons, 1995.

[5] A. Bornhauser, K. Kromp, and R. F. Pabst, "R-curve evaluation with ceramic materials at elevated temperatures by an energy approach using direct observation and compliance calculation of the crack length," Journal of Materials Science, vol. 20, no. 7, pp. 2586-2596, 1985.

[6] M. R. Ayatollahi, M. R. M. Aliha, and M. M. Hassani, "Mixed mode brittle fracture in PMMA - an experimental study using SCB specimens," Materials Science and Engineering A, vol. 417, no. 1-2, pp. 348-356, 2006.

[7] F. Berto and P. Lazzarin, "Recent developments in brittle and quasi-brittle failure assessment of engineering materials by means of local approaches," Materials Science and Engineering R: Reports, vol. 75, no. 1, pp. 1-48, 2014.

[8] A. Hodgkins, T. J. Marrow, M. R. Wootton, R. Moskovic, and P. E. J. Flewitt, "Fracture behaviour of radiolytically oxidised reactor coregraphites: a view," Materials Science and Technology, vol. 26, no. 8, pp. 899-907, 2010.

[9] S. Sato, H. Awaji, K. Kawamata, A. Kurumada, and T. Oku, "Fracture criteria of reactor graphite under multiaxial stesses," Nuclear Engineering and Design, vol. 103, no. 3, pp. 291-300, 1987.

[10] M. R. Ayatollahi, F. Berto, and P. Lazzarin, "Mixed mode brittle fracture of sharp and blunt V-notches in polycrystalline graphite," Carbon, vol. 49, no. 7, pp. 2465-2474, 2011.

[11] P. Lazzarin, F. Berto, and M. R. Ayatollahi, "Brittle failure of inclined key-hole notches in isostatic graphite under inplane mixed mode loading," Fatigue and Fracture of Engineering Materials and Structures, vol. 36, no. 9, pp. 942-955, 2013.

[12] R. K. L. Su, H. H. Chen, S. L. Fok et al., "Determination of the tension softening curve of nuclear graphites using the incremental displacement collocation method," Carbon, vol. 57, pp. 65-78, 2013.

[13] H. Li, J. Li, G. Singh, and A. Fok, "Fracture behavior of nuclear graphite NBG-18," Carbon, vol. 60, pp. 46-56, 2013.

[14] M. Mostafavi, M. J. J. Schmidt, B. J. Marsden, and T. J. Marrow, "Fracture behaviour of an anisotropic polygranular graphite
(PGA)," Materials Science and Engineering A, vol. 558, pp. 265277, 2012.

[15] T. H. Becker, T. J. Marrow, and R. B. Tait, "Damage, crack growth and fracture characteristics of nuclear grade graphite using the Double Torsion technique," Journal of Nuclear Materials, vol. 414, no. 1, pp. 32-43, 2011.

[16] R. Moskovic, P. J. Heard, P. E. J. Flewitt, and M. R. Wootton, "Overview of strength, crack propagation and fracture of nuclear reactor moderator graphite," Nuclear Engineering and Design, vol. 263, pp. 431-442, 2013.

[17] B. Stalder, P. Béguelin, and H. H. Kausch, "A simple velocity gauge for measuring crack growth," International Journal of Fracture, vol. 22, no. 2, pp. R47-R50, 1983.

[18] A. Hodgkins, T. J. Marrow, P. Mummery, B. Marsden, and A. Fok, "X-ray tomography observation of crack propagation in nuclear graphite," Materials Science and Technology, vol. 22, no. 9, pp. 1045-1051, 2006.

[19] DANTEC, "Measurement Principles-Digital Image Correlation (DIC)," 2012.

[20] R. Lichtenberger and H. Schreier, "Non-contacting measurement technology for component safety assessement," in Proceedings of the 6th International Symposium and Exhibition on Sophisticated Car Occupant Safety Systems (AIRBAG '02), Karlsruhe, Germany, 2002.

[21] J. Abanto-Bueno and J. Lambros, "Investigation of crack growth in functionally graded materials using digital image correlation," Engineering Fracture Mechanics, vol. 69, no. 14-16, pp. 1695-1711, 2002.

[22] S. J. Orfanidis, Optimum Signal Processing, McGraw-Hill, New York, NY, USA, 2007.

[23] M. R. Ayatollahi and M. Moazzami, "Digital image correlation method for calculating coefficients of Williams expansion in compact tension specimen," Optics and Lasers in Engineering, vol. 90, pp. 26-33, 2017.

[24] R. Markgraaff, Relationship between the natural frequencies and fatigue life of NBG-18 graphite [M.S. thesis], North-West University, Potchefstroom, South Africa, 2010.

[25] Wikipedia, "Cross-correlation," 2013.

[26] MathWorks, "Matlab the language of Technical Computing," 2013.

[27] A. Hodgkins, J. Marrow, P. Mummery, A. Fok, and B. J. Marsden, "Crack propagation resistance and damage mechanisms in nuclear graphite," in Fracture of Nano and Engineering Materials and Structures: Proceedings of the 16th European Conference of Fracture, Alexandroupolis, Greece, July 3-7, 2006, E. E. Gdoutos, Ed., pp. 891-892, Springer, Dordrecht, The Netherlands, 2006. 


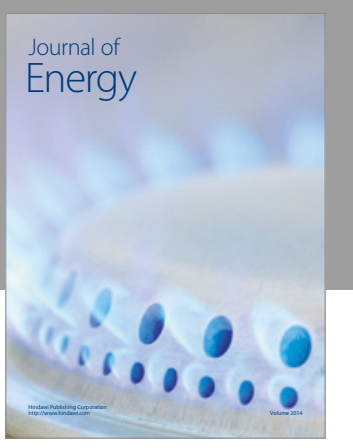

Journal of

Industrial Engineering
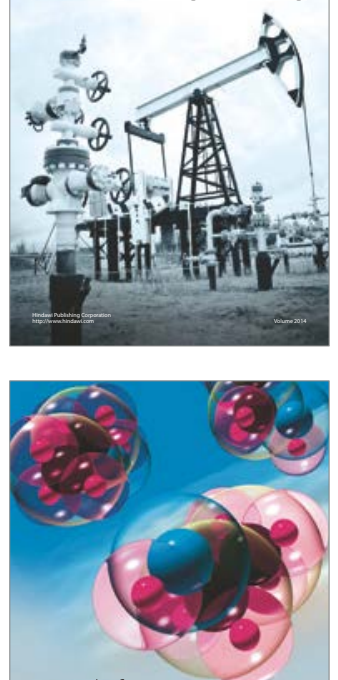

Fuels
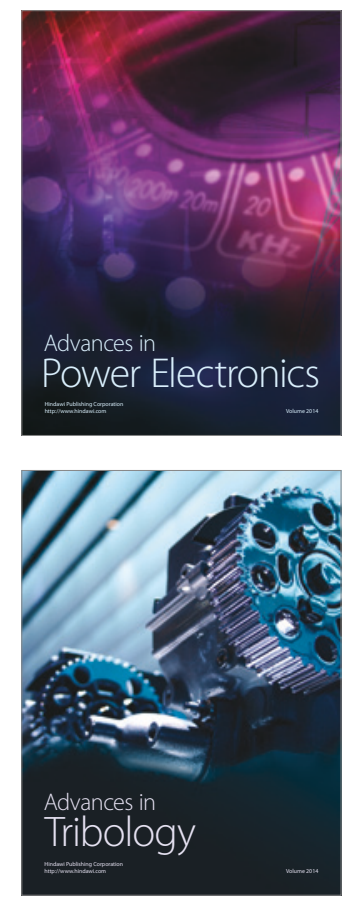
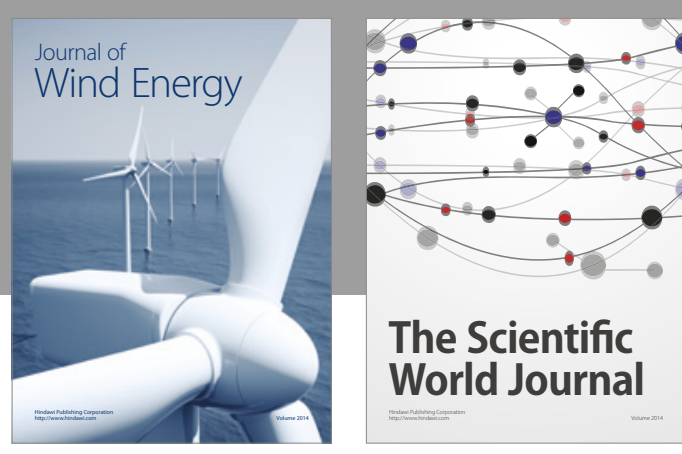

The Scientific World Journal
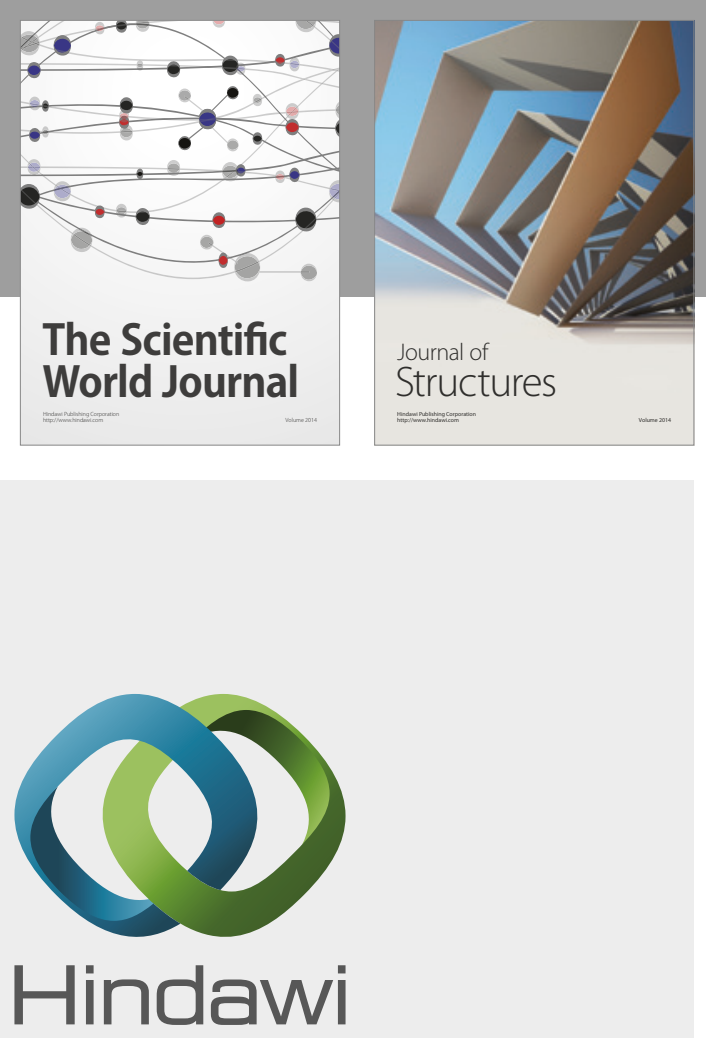

Submit your manuscripts at

https://www.hindawi.com
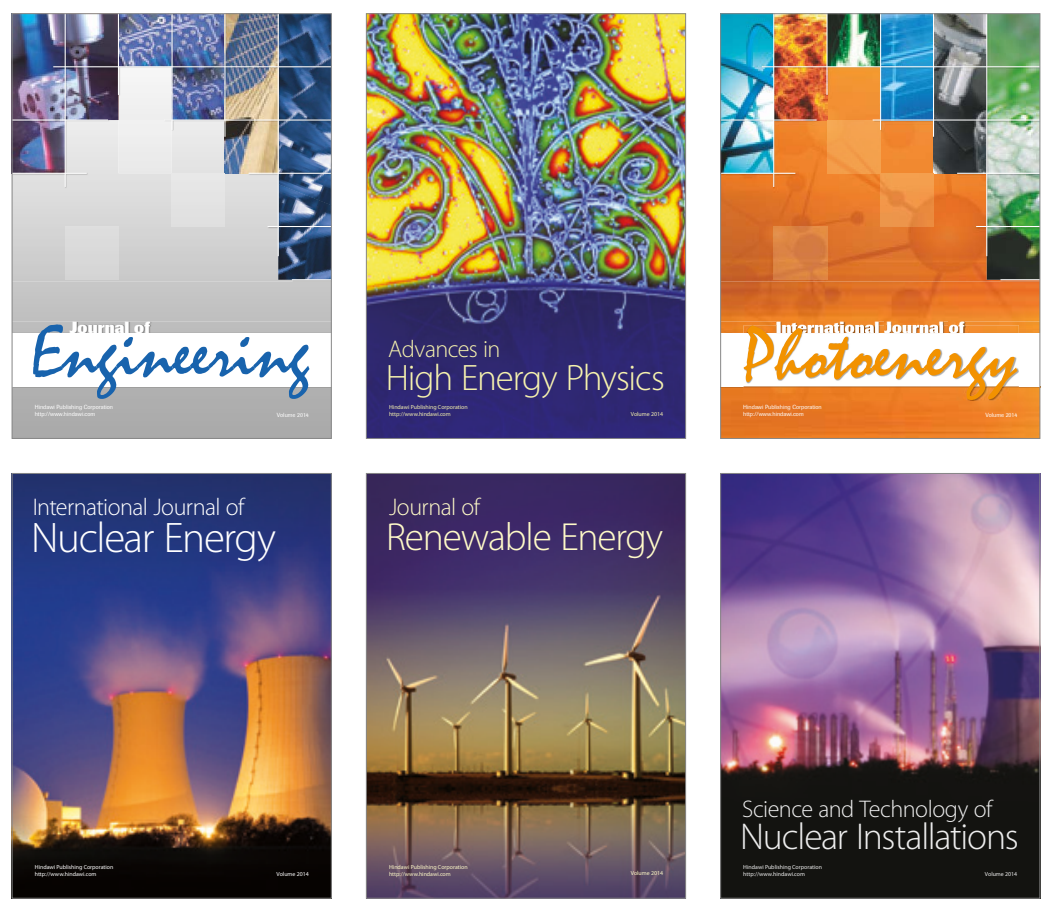

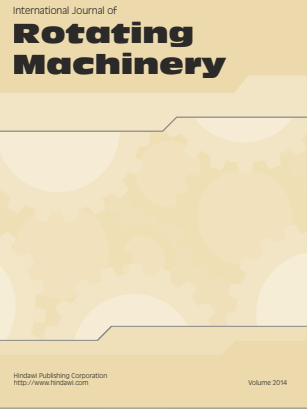

Journal of

Petroleum Engineering

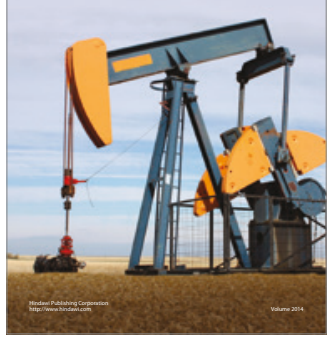

Journal of
Solar Energy
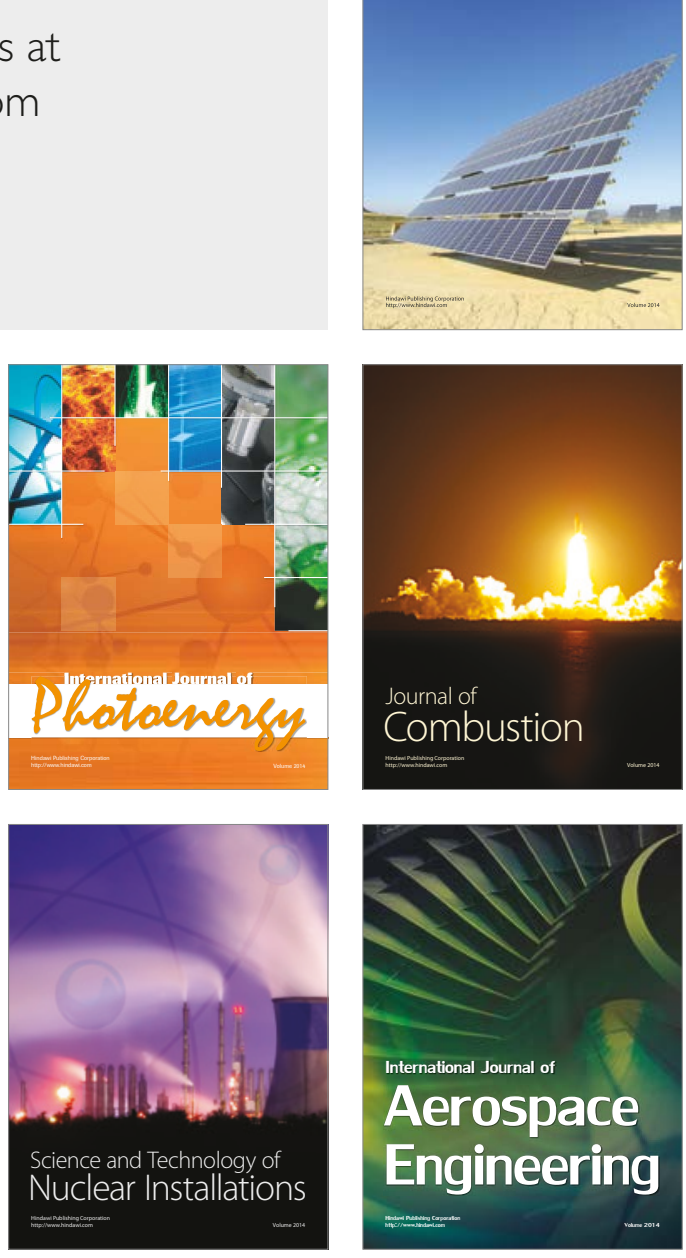